\title{
The significance of feeding history on the value of heterotrophic microzooplankton as prey for larval crabs
}

\author{
Stephen D. Sulkin*, Gene L. McKeen \\ Shannon Point Marine Center, 1900 Shannon Point Road, Anacortes, Washington 98221, USA
}

\begin{abstract}
Larvae of 4 species of crabs of the genus Cancer (C. gracilis, C. magister, $C$. oregonensis and $C$. productus) were raised in the laboratory from hatching to the post-larval megalopa stage on diets of nauplii of the brine shrimp Artemia sp. and on 2 diets of the rotifer Brachionus plicatilis. One of the rotifer diets had been cultured on the chlorophyte Dunaliella tertiolecta, the other on the chrysophyte Isochrisis galbana. In 3 of the $4 \mathrm{crab}$ species, Dunaliella-fed rotifers did not support development to the megalopa, whereas Isochrisis-fed rotifers did. In the fourth species, $C$. productus, survival to the megalopa was only $1 \%$ on Dunaliella-fed rotifers, whereas Isochnisis-fed rotifers supported development equal to that of the Artemia-fed control. Differences between the 2 rotifer diets were evident in all species by Stage 3, although the first significant accurrence of increased mortality on the Dunaliellafed rotifer diet varied among species. In all 4 species, development rate was faster as early as the first molt on the Isochrisis-fed rotifer diet as compared to the Dunaliella-fed rotifer diet, a difference maintained throughout development. Only in C. Gracilis did survival to the megalopa on the Isochrisis-fed rotifer fall substantially below that seen for Artemia-fed larvae. Stage mortality on the Isochrisis-fed rotifer diet typically equaled that of the Artemia sp. control. Differences in development rates between the Isochrisis-fed rotifer diet and the Artemia sp. diet varied among species, as did megalopa weight. We attribute differences between the 2 rotifer diets to the high content of long-chain $\omega-3$ polyunsaturated fatty acids in I. galbana and their absence in $D$. tertiolecta. The value of heterotrophic microzooplankton as prey for crab larvae, either in culture or in nature, will depend upon the prey's own feeding history
\end{abstract}

KEY WORDS: Crab larvae $\cdot$ Diet $\cdot$ Heterotrophs $\cdot$ Microzooplankton

\section{INTRODUCTION}

The pelagic larval stages of most species of brachyuran crabs are planktotrophic; that is, they must feed on particulate matter in the plankton to satisfy their nutritional requirements. Levine \& Sulkin (1984) demonstrated that such larvae require not only food energy to support their metabolic needs, but also a dietary source of specific nutrients such as long-chain $\omega-3$ polyunsaturated fatty acids (PUFA) to support development to metamorphosis.

In support of efforts to culture brachyuran crab larvae in the laboratory, a wide variety of prey organisms have been tested (Sulkin 1975, Bigford 1978, Harms \&

•E-mail: sulkin@cc.wwu.edu
Seeger 1989). Most of these studies indicated that development was sustained to metamorphosis only on small, motile animal prey and that unicellular algae were not effective diets. Based on these results, it has been assumed that animal prey such as larval forms of other invertebrates must be important components of the diet in nature. However, recent studies have demonstrated that both autotrophic and heterotrophic protists can contribute to the dietary needs of brachyuran larvae (Lehto et al. 1998, Sulkin et al. 1998).

The ability of larval crabs to utilize heterotrophic microzooplankton may provide a link between the rich carbon sources of the microbial food web and metazoans. In the coastal waters inhabited by larvae of many crab species, greater than $50 \%$ of total primary production can be attributed to algal cells less than 
$5 \mu \mathrm{m}$ in diameter (Throndsen 1979, Joint \& Pomroy 1983). Heterotrophic microzooplankton are the primary consumers of these small cells and can repackage them into biomass of a suitable size to be preyed upon by larger planktonic organisms (Gifford 1991, Sanders \& Wickham 1993). Sulkin et al. (1998) suggested that while such protistan diets may not be sufficient to sustain development, they may be important as supplemental sources of nutrition or when other, more favorable prey are not available in sufficient densities.

The potential for heterotrophic microzooplankton to serve as a significant source of nutrition for crab larvae begs the question of how their own nutritional ecology influences their quality as prey. Our study addresses this question experimentally by manipulating the diet of a heterotrophic prey organism of known dietary effectiveness for larval crabs: the rotifer Brachionus plicatilis. Sulkin (1978) and Sulkin \& Van Heukelem (1980) showed that early larval stages of a number of crab species developed well on rotifers that had been cultured on a diet of the chlorophyte Dunaliella tertiolecta. However, this rotifer diet frequently did not support development to the post-larval megalopa stage or it resulted in reduced survival and delayed development as compared to control diets. Supplementing the Dunaliella-fed rotifer with microcapsules containing long-chain $\omega-3$ PUFA, however, resulted in increased survival equal to that of the control (Levine \& Sulkin 1984). Volkman et al. (1989) reported that $D$. tertiolecta is very low in such long-chain PUFA, a result that implies that the quality of the rotifer as prey may have been influenced by its diet. In the present study, we manipulated the rotifer prey by culturing it in the laboratory on the chrysophyte Isochrisis galbana, reported by Volkman et al. (1989) to contain significant pools of long-chain $\omega$-3 PUFA. By comparing the development of crab larvae raised on rotifers that have been cultured on the 2 different algal diets, we have addressed the question of whether the diet of heterotrophic prey influences its quality as prey for crab larvae.

\section{METHODS}

Experimental approach. In order to provide an effective test of the hypothesis that the nutritional value of heterotrophic prey will depend upon its own diet, the experiments were carried out on the larval stages of 4 species of the genus Cancer that co-exist in the inland waters of the Puget Sound basin. The adults of the 4 species C. oregonensis, C. gracilis, C. productus, and C. magister range in size at maturity from 8 to $170 \mathrm{~mm}$ in carapace width (Hines 1991), suggesting possible variation in reproductive tactic (Strathmann \& Strathmann 1982, Hines 1991). Indeed, their larvae have been shown to differ in various aspects of development (Sulkin \& McKeen 1994).

Larvae obtained from each of the 4 Cancer species were raised in laboratory culture from hatching to the megalopal stage on 3 diets, including freshly hatched nauplii of the brine shrimp Artemia sp. (Art), Dunaliella-fed rotifers (Dun-rot), and Isochrisis-fed rotifers (Iso-rot). Survival through successive zoeal stages, percent mortality that occurred during each stage, time of development through successive stages, and dry weight of megalopae were compared among diet treatments for each species.

Obtaining larvae. Egg-bearing female Cancer magister were collected by SCUBA from an eelgrass bed (Zostera marina) located adjacent to the laboratory at the Shannon Point Marine Center in Anacortes, WA, USA. C. productus were collected by ring-net at the lower intertidal on the beach at Shannon Point. Both $C$. oregonensis and $C$. gracilis were coilected by trawling. Egg-bearing females of $C$. magister and C. productus were held in running seawater at ambient conditions (approximately $8^{\circ} \mathrm{C}$ and salinity of 30 ) until hatching of larvae occurred. C. oregonensis and C. gracilis were held individually in $200 \mathrm{~mm}$ diameter glass bowls until hatching. Water temperature was maintained at $10^{\circ} \mathrm{C}$ and salinity at 30 .

For Cancer magister and C. productus, newly hatched larvae were collected with a $180 \mu \mathrm{m}$ sieve and placed in 110 mm diameter glass bowls filled with filtered seawater. C. oregonensis and C. gracilis larvae were transferred from the hatching bowl to a clean $110 \mathrm{~mm}$ diameter glass bowl filled with filtered seawater. Larvae from 1 brood were used for C. magister, C. productus, and C. gracilis and from 2 broods for C. oregonensis.

The following general protocol was used for all 4 species in setting up the experiment. For each mass bowl of newly hatched larvae, thirty $75 \mathrm{~mm}$ diameter glass bowls were set up, each containing 10 larvae. The bowls were then distributed randomly among the 3 diet treatments described below. Thus, for Cancer magister and C. productus, 10 bowls (100 larvae) were assigned to each of the 3 treatments. For $C$. oregonensis, a total of 20 bowls from 2 broods (200 larvae) were assigned to each treatment. Due to comparatively small brood size and the desire to assign siblings to all 3 treatments, the C. gracilis experiment included 10 bowls (100 larvae) assigned to the control, but only 5 bowls (50 larvae) to each of the rotifer treatments. Larvae for all species were fed the appropriate diet on the first day and placed into a temperature-light controlled incubator at $15^{\circ} \mathrm{C}$ and $14 \mathrm{~h}$ light:10 h dark. The temperature selected was based on the results of Sulkin \& McKeen (1994) that indicated that $15^{\circ} \mathrm{C}$ would provide both good survival and development time. 
Experimental diets. The rotifer Brachionus plicatilis was cultured in the laboratory on either the chlorophyte Dunaliella tertiolecta or the chrysophyte Isochrisis galbana. Large volumes of both algal species were grown from starter cultures by inoculating 3 l flasks for D. tertiolecta and $20 \mathrm{l}$ carboys for I. galbana and adding appropriate amounts of $f / 2$ medium (Sulkin \& Epifanio 1975). After 2 to 4 d, algal cultures were dense enough to feed the rotifer cultures by drawing off $i \mathrm{l}$ of $D$. tertiolecta or $3 \mathrm{l}$ of $I$. galbana and adding it to a $3 \mathrm{l}$ flask into which a small group of rotifers was added. The respective algal cultures were then replenished with $5 \mu \mathrm{m}$ filtered seawater and appropriate volumes of $f / 2$ medium. These rotifer 'starter' cultures were maintained in an incubation chamber at $15^{\circ} \mathrm{C}$ under constant light, temperature, and aeration. When algal density in the rotifer culture flasks began to diminish visibly, the rotifers were harvested for use as prey. The rotifers were collected on a $45 \mu \mathrm{m}$ sieve and rinsed with filtered seawater into a glass bowl from which they were drawn by pipette for feeding the crab larval cultures. Excess rotifers were then used to re-inoculate an algal culture for future use. Rotifers were harvested in this fashion daily for use as prey.

Artemia sp. nauplii were hatched daily from dried eggs (Aquarium Products) placed into filtered seawater in a glass flask. The flask was aerated and illuminated for $28 \mathrm{~h}$. Newly hatched nauplii were collected on a $180 \mu \mathrm{m}$ sieve and resuspended in a glass bowl containing filtered seawater. Nauplii were added to the crab culture bowls by pipette.

Experimental protocol. On a daily basis from hatching to molt to the megalopa, larvae in each bowl were transferred to clean seawater and fed the appropriate diet. Prey were added 'in excess'; that is, in sufficient quantities that there were still ample prey available to the larvae after $24 \mathrm{~h}$. As larvae in each bowl were transferred, data were collected on numbers of those which had survived and molted. Experiments were conducted until all larvae had either died or molted to the megalopa for each treatment.

Analysis of the data included calculations of percent survival for each bowl of larvae through successive zoeal stages for each treatment. Percent survival was then calculated for all bowls in a treatment at each successive stage of development and plotted as a function of zoeal stage for each treatment in each species. In order to compare the treatment effects rigorously for each zoeal stage independently, percent mortality that occurred in each bowl during each zoeal stage was calculated. Values were transformed by arcsine transformation and mean percent mortalities for each zoeal stage were compared among (3) or between ( 2 surviving) treatments using parametric analysis of variance (ANOVA) or Student's $t$-tests respectively. Where ANOVA was significant $(\mathrm{p}<$ 0.05), means were further distinguished by a Tukey's honestly significant difference (HSD) pairwise comparison $(\mathrm{p}=0.05)$ (Zar 1996).

Durations of successive zoeal stages were determined by calculating mean days of successive molts based on all molts occurring in all culture bowls assigned to a particular treatment for each molting event. Because of non-homogeneous variances typical of such results, treatments were compared at each molt by the non-parametric Kruskal-Wallis ANOVA, followed by a non-parametric pairwise comparison of mean ranks tests $(p=0.05)$. Where only 2 treatments were compared, a rank sum test was used (Zar 1996).

Megalopal weights. A common approach was used to determine megalopal weights as a function of diet treatment for all 4 species. Because no megalopae were obtained in the Dun-rot treatment, data were collected only in the Art and Iso-rot treatments. When a megalopa was obtained from the culture, it was rinsed with freshwater, blotted dry, and placed in a preweighed aluminum boat that was then held in a drying oven at $100^{\circ} \mathrm{C}$. The boat and dried megalopa were then weighed to the nearest $0.1 \mathrm{mg}$. Because of differential mortality between treatments during zoeal development, sample sizes varied between treatments. A 2-sample $t$-test was used to compare mean values between treatments for each species.

\section{RESULTS}

\section{Survival}

In 3 of the 4 crab species (Cancer gracilis, C. magister and $C$. oregonensis), larvae fed the Dunaliella-fed rotifer (Dun-rot) diet did not survive to the megalopa (Fig 1). However, in all 4 crab species, larvae fed the Isochrisis-fed rotifer (Iso-rot) diet survived to that stage. Indeed, among these 3 crab species, only in C. gracilis did Iso-rot larvae show substantially reduced survival to the megalopa as compared to the Artemia sp. (Art) control. The fourth species (C. productus) showed only $1 \%$ survival to the megalopa on the Dunrot diet, while larvae of this species fed the Art and Iso-rot diets showed equal survival to the megalopa.

To assess the effects of diet on each zoeal stage independently, we calculated percent mortality that occurred during each stage and compared them among treatments (Table 1). In C. gracilis, significant differences among treatments first occurred during Stage 4, with Dun-rot larvae showing increased mortality over the other 2 treatments. During the fifth (final) zoeal stage, mortality was equally high on both rotifer diets, although some Iso-rot larvae survived to 
Table 1. Cancer gracilis, C. magister, C. oregonensis, and C. productus. Mean percent mortalities during each zoeal stage for the 3 diet treatments tested. Statistical analysis involves ANOVA or 2 -sample $t$-test as described in the text $(p=0.05$ except where noted). Art (A): Artemia sp. nauplius; D-rot (D): Dunaliella tertiolecta-fed rotifer; I-rot (I): Isochrisis galbanafed rotifer; nsd: no significant difference

\begin{tabular}{|c|c|c|c|c|}
\hline \multirow[t]{2}{*}{ Zoeal stage } & \multicolumn{3}{|c|}{ Diet treatment } & \multirow{2}{*}{$\begin{array}{c}\text { Statistical } \\
\text { analysis }\end{array}$} \\
\hline & Art & D-rot & I-rot & \\
\hline \multicolumn{5}{|c|}{ Cancer gracilis } \\
\hline 1 & 13.0 & 14.0 & 6.0 & nsd \\
\hline 2 & 0 & 4.2 & 4.2 & nsd \\
\hline 3 & 4.9 & 37.4 & 2.2 & nsd \\
\hline 4 & 0 & 63.3 & 9.0 & $D>I=A$ \\
\hline 5 & 19.4 & 100.0 & 88.4 & $D=I>A$ \\
\hline \multicolumn{5}{|c|}{ Cancer magister } \\
\hline 1 & 9.0 & 14.0 & 16.0 & nsd \\
\hline 2 & 1.0 & 14.6 & 1.1 & $D>A=I$ \\
\hline 3 & 0 & 100.0 & 3.8 & $D>A=I$ \\
\hline 4 & 2.1 & - & 17.9 & $\mathrm{I}>\mathrm{A}$ \\
\hline 5 & 42.0 & - & 45.6 & nsd \\
\hline \multicolumn{5}{|c|}{ Cancer oregonensis } \\
\hline 1 & 8.5 & 3.5 & 3.0 & nsd \\
\hline 2 & 2.2 & 25.6 & 2.6 & $D>A=I$ \\
\hline 3 & 0.5 & 77.3 & 14.7 & $D>A=I$ \\
\hline 4 & 3.4 & 100 & 33.2 & $\mathrm{D}>\mathrm{I}>\mathrm{A}$ \\
\hline 5 & 76.1 & - & 72.0 & nsd \\
\hline \multicolumn{5}{|c|}{ Cancer productus } \\
\hline 1 & 2.0 & 3.0 & 7.0 & nsd \\
\hline 2 & 1.0 & 1.0 & 0 & nsd \\
\hline 3 & 2.0 & 15.4 & 0 & $\mathrm{D}>\mathrm{A}=\mathrm{I}$ \\
\hline 4 & 5.3 & 15.5 & 4.2 & $D>A=I$ \\
\hline 5 & 21.8 & 98.0 & 19.5 & $D>A=I$ \\
\hline
\end{tabular}

the megalopa. High mortality during the fifth zoeal stage on the Iso-rot diet produced the low survival to the megalopa apparent in Fig. 1 for larvae raised on this diet.

In Cancer magister, there were no differences among treatments in mortality during Stage 1, with mortality significantly higher in Dun-rot larvae than in the other 2 treatments in both Stages 2 and 3 (Table 1 ). No Dun-rot larvae survived to Stage 4 . Iso-rot larvae showed significantly higher mortality during Stage 4 as compared to Art larvae, but mortality was the same during Stage 5 for both treatments.

Cancer oregonensis showed a pattern of mortality among treatments similar to that shown for $C$. magister, except that some Dun-rot larvae survived into Stage 4 (Table 1). As with C. magister, C. oregonensis larvae showed higher mortality during Stage 4 on the Iso-rot diet than on Art, although there was no significant difference between the diets during Stage 5 .

In Cancer productus, Iso-rot larvae showed no difference in mortality compared to the Art control for any stage (Table 1). Mortality was significantly higher for Dun-rot larvae during the last 3 stages.

\section{Mean days of molt}

Cumulative duration of zoeal development through successive stages varied among the 4 species (Table 2). In Cancer gracilis, Iso-rot larvae showed consistently faster development through zoeal Stage 3 than was the case for Dun-rot and Art larvae. By the end of Stage 4, Art and Iso-rot larvae showed the same time of development, a result that was also evident by the end of Stage 5 (molt to the megalopa). This indicates that during zoeal Stage 4, Iso-rot larvae were developing more slowly than were Art larvae. There was no difference in time of development between the 2 diets during Stage 5 or in total time to the megalopa.

In Cancer magister, development was consistently faster for Art larvae than for Iso-rot larvae, with both treatments supporting faster development during the first 2 stages than was the case for Dun-rot larvae (Table 2). Development to the megalopa was $20 \%$ faster on the Art treatment.

In Cancer oregonensis, Iso-rot larvae developed faster during Stage 1 than did larvae fed the other 2 treatments (Table 2). However, in succeeding development, Art larvae developed consistently faster than did

Table 2. Cancer gracilis, C. magister, C. oregonensis, and C. productus. Mean days of successive molts for the 3 diet treatments tested. Statistical analysis involves Kruskal-Wallis ANOVA or rank sum test as described in the text $(\mathrm{p}=0.0 .5$ except where noted). Diet treatment symbols as in Table 1

\begin{tabular}{|lrrrr|}
\hline \multirow{2}{*}{ Molt no. } & \multicolumn{3}{c}{ Diet treatment } & Statistical \\
& Art & D-rot & I-rot & analysis \\
\hline Cancer gracilis & & & & \\
1 & 7.3 & 7.7 & 6.5 & $\mathrm{I}<\mathrm{A}=\mathrm{D}$ \\
2 & 13.5 & 13.6 & 11.7 & $\mathrm{I}<\mathrm{A}=\mathrm{D}$ \\
3 & 19.5 & 20.7 & 17.5 & $\mathrm{I}<\mathrm{A}<\mathrm{D}$ \\
4 & 25.8 & 30.6 & 25.5 & $\mathrm{I}=\mathrm{A}<\mathrm{D}$ \\
5 & 34.1 & - & 35.0 & $\mathrm{~A}=\mathrm{I}$ \\
Cancer magister & & & & \\
1 & 8.6 & 9.8 & 9.0 & $\mathrm{~A}<\mathrm{I}<\mathrm{D}$ \\
2 & 14.8 & 23.0 & 16.1 & $\mathrm{~A}<\mathrm{I}<\mathrm{D}$ \\
3 & 21.2 & - & 24.5 & $\mathrm{~A}<\mathrm{I}(0.001)$ \\
4 & 29.2 & - & 37.1 & $\mathrm{~A}<\mathrm{I}(0.001)$ \\
5 & 41.6 & - & 52.3 & $\mathrm{~A}<\mathrm{I}(0.001)$ \\
Cancer oregonensis & & & & \\
1 & 7.0 & 7.0 & 6.6 & $\mathrm{I}<\mathrm{A}=\mathrm{D}$ \\
2 & 11.9 & 15.9 & 12.6 & $\mathrm{~A}<\mathrm{I}<\mathrm{D}$ \\
3 & 17.7 & 27.5 & 19.5 & $\mathrm{~A}<\mathrm{I}<\mathrm{D}$ \\
4 & 25.2 & - & 27.3 & $\mathrm{~A}<\mathrm{I}(0.001)$ \\
5 & 34.8 & - & 37.0 & $\mathrm{~A}<\mathrm{I}(0.001)$ \\
Cancer productus & & & & \\
1 & 7.8 & 8.5 & 8.1 & $\mathrm{D}>\mathrm{I}>\mathrm{A}$ \\
2 & 14.0 & 17.7 & 14.9 & $\mathrm{D}>\mathrm{I}>\mathrm{A}$ \\
3 & 20.8 & 30.5 & 21.6 & $\mathrm{D}>\mathrm{I}>\mathrm{A}$ \\
4 & 28.6 & 46.6 & 29.9 & $\mathrm{D}>\mathrm{I}>\mathrm{A}$ \\
5 & 40.2 & 59.0 & 41.7 & $\mathrm{~A}<\mathrm{I}(0.001)$ \\
& & & & \\
\hline & & & & \\
& & &
\end{tabular}


Cancer oregonensis

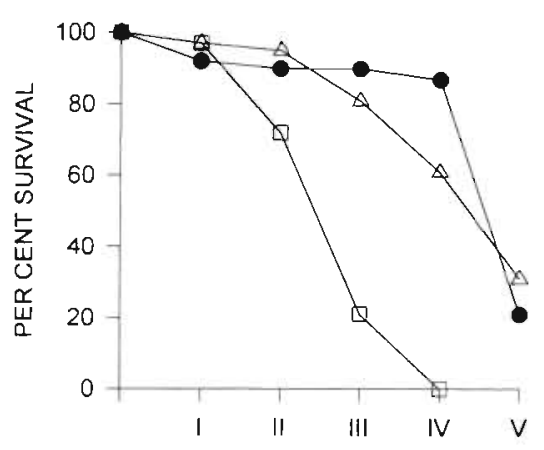

Cancer gracilis

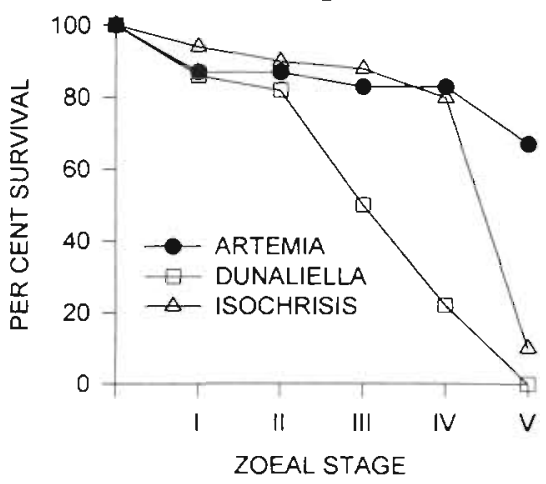

Fig. 1. Percent survival through successive zoeal stages for larvae of 4 species of Cancer raised on each of the 3 indicated diets

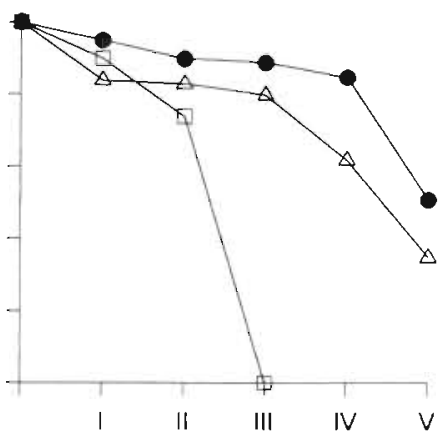

Cancer productus

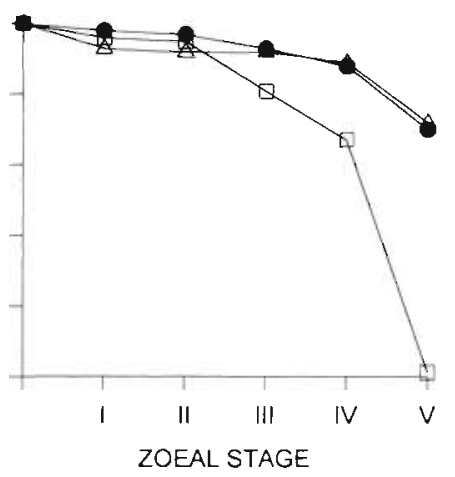

\section{Megalopal weight}

\section{DISCUSSION}

It is clear from data on both survival and development rate that the prey upon which the rotifer had been cultured had a substantial effect on the value of the rotifer as prey for larvae of all 4 crab species. Rotifers cultured on the chrysophyte Isochrisis galbana supported higher survival throughout larval development than did rotifers cultured on the chlorophyte Dunaliella tertiolecta. The effect upon survival through successive zoeal stages was evident in all species by zoeal Stage 3, although the first significant occurrence of increased mortality during a specific zoeal

larvae on either rotifer diet. However, at every molt, Iso-rot larvae developed faster than did Dun-rot larvae. Development to the megalopa on the Art diet as compared to the Iso-rot was $8 \%$ faster.

Finally, Cancer productus larvae developed consistently faster on the Art diet than on either of the 2 rotifer treatments, while Iso-rot larvae always molted sooner than did Dun-rot larvae (Table 2). Development to the megalopa was $3.5 \%$ faster on the Art diet.

Table 3. Cancer gracilis, C. magister, C. oregonensis, and $C$. productus. Mean dry weights (mg) for megalopae of the 4 species of Cancer when zoeae were raised on the Artemia sp. nauplius diet (Art) and the Isochrisis-fed rotifer diet (Iso-rot). One standard deviation is shown in parentheses for each mean. Results of a 2 -sample $t$-test are shown.

\begin{tabular}{|lccc|}
\hline Species & \multicolumn{2}{c|}{ Diet } & $\begin{array}{c}\text { 2-sample } \\
t \text {-test }\end{array}$ \\
\hline A.rt & Iso-rot & \\
C. gracilis & $0.24(0.04)$ & $0.18(0.03)$ & $<0.05$ \\
C. oregonensis & $1.38(0.23)$ & $1.11(0.25)$ & $<0.001$ \\
C. productus & $0.48(0.11)$ & $0.43(0.19)$ & $>0.05$ \\
& $0.62(0.08)$ & $0.68(0.17)$ & $<0.01$ \\
\hline
\end{tabular}

stage varied among species (Table 1). Cancer magister appeared the most negatively affected by the Dun-rot diet, although only in 1 species, $C$. productus, did this diet support any survival to the megalopa. In this case, only 1 zoea successfully molted to the megalopa.

Differences between the 2 rotifer diets were also shown in development rate. In all 4 crab species, development was faster on the Iso-rot diet than on the Dun-rot diet as early as the first molt. This difference was maintained throughout development. Because survival to the megalopa was essentially non-existent on the Dun-rot diet, a comparison of megalopal weights between the 2 treatments was not possible.

Results reported here for survival to the megalopa on the Dun-rot diet are consistent with previous reports on the value of this diet. Sulkin \& Norman (1976) reported that larvae of the xanthid crabs Rhithropanopeus harrisii and Neopanope texana could survive to the megalopa on the Dun-rot diet, but development was significantly delayed as compared to a diet of freshly hatched brine shrimp. A similar result was reported by Sulkin \& Van Heukelem (1980) for the deep-sea red crab Geryon quinquedens. However neither the blue crab Callinectes sapidus (Sulkin 1978) nor the stone crab Menippe mercenaria (Sulkin \& Van 
Heukelem 1980) survived to the megalopa on the Dunrot diet. The results reported here for the 4 species of Cancer crabs are most similar to the results for the blue and stone crabs. As reported for C. sapidus (Sulkin 1978), Cancer species can be sustained through early development on the Dun-rot diet. However, the diet lacks some nutritional constituent that is apparently required for continued development and ultimate molting to the megalopa.

Levine \& Sulkin (1984) suggested that the Dun-rot diet was lacking in long-chain PUFA of the $\omega-3$ pathway. When they supplemented the Dun-rot diet with microcapsules containing docosahexaenoic acid (22:6w3), development in the crab Eurypanopeus depressus was accelerated and survival increased to equal that of the Art diet. This hypothesis received support from the work of Volkman et al. (1989), who reported that Dunaliella tertiolecta contained little or no long-chain PUFA (C20-22) of the $\omega-3$ pathway.

Our study lends further support to the hypothesis that crab larvae benefit from a diet that includes longchain $\omega-3$ PUFA by showing that when the rotifer prey is fed Isochrisis galbana, an alga comparatively high in long-chain $\omega$-3 PUFA (Volkman et al. 1989), crab larval survival is increased and development accelerated over that seen when the larvae are fed the Dun-rot diet. Indeed, in the case of Cancer crabs, only rotifers cultured on I. galbana supported development of crab larvae to the megalopa.

The results also illustrate that the heterotrophic rotifer prey was passing on to its crab predator dietary constituents from lower in the food chain that are important in supporting crab larval development. Just as crab larvae appear to be unable to manufacture long-chain $\omega$-3 PUFA from the shorter-chain $\omega$-3 precursors that are provided by Dunaliella tertiolecta (Levine \& Sulkin 1984), so too are the rotifers. For the rotifer to contribute the necessary dietary constituents, it must receive them itself via its own diet.

In general, larvae of all 4 crab species fared well on the Iso-rot diet as compared to the Art control. Only in Cancer gracilis, where mortality during the fifth (final) zoeal stage was much higher on the Iso-rot than on the Art diet, was overall survival to the megalopa substantially different between the 2 diet treatments. In only 3 stages out of 20 cases among the 4 species was individual stage mortality significantly higher on the Isorot diet than on the Art diet including the aforementioned Stage 5 C. gracilis, Stage 4 C. magister, and Stage $4 \mathrm{C}$. oregonensis; Table 1 ). With only a few exceptions, however, development rate was typically delayed on the Iso-rot diet as compared to the Art diet. This result is similar to that reported by Levine \& Sulkin (1984) in which the Dun-rot diet, supplemented by microcapsules containing long-chain $\omega-3$ PUFA, resulted in survival equal to the Art control, but also in prolonged development. It seems likely that the Art diet may be providing other nutritional constituents in addition to long-chain $\omega-3$ PUFA that promote more rapid development in crab larvae.

Our results have consequence both to laboratory culture techniques and to examination of natural diets for crab larvae. Microzooplankton with rapid growth potential in culture may prove useful in large-scale production of crab larvae either for research or aquaculture purposes. However, when using heterotrophic species, it will be important to determine not only which autotrophic diets will produce favorable growth in culture of the heterotrophic microzooplankton to be used as crab larval prey, but also whether those autotrophs are providing the nutrients necessary to sustain larval development of the target crab species. Although some heterotrophic microzooplankton may be able to synthesize essential nutrients required by crab larvae from precursors provided by the heterotroph's autotrophic diet, others, like the rotifers in this study, are able only to pass along essential nutrients obtained in their diets. Hence, the value of microzooplankton as prey for crab larvae in nature will likely be determined by the prey's feeding history. An assessment of the role played by these heterotrophic prey in nature will require analysis of the food web relationships of all appropriate predator-prey interactions or, at least, a qualitative analysis of the heterotrophic prey to determine their potential nutritional value. It should be noted that the rotifer diets used in the present study are metazoan microzooplankton. Sulkin et al. (1998) have shown that Cancer magister larvae can consume and gain nutrition from heterotrophic dinoflagellates, a potentially important source of nutrition in first-feeding larvae. The role of previous diet in determining the quality of heterotrophic protists as prey for crab larvae deserves investigation.

Acknowledgements. This research was supported in part by a grant from the Washington Sea Grant Program and by the Shannon Point Marine Center, Western Washington Unjversity.

\section{LITERATURE CITED}

Bigford TE (1978) Effect of several diets on survival, development time, and growth of laboratory reared spider crab, Libinia emarginata, larvae. Fish Bull US 76:59-64

Gifford DJ (1991) The protozoan-metazoan trophic link in pelagic ecosystems. J Protozool 38:81-86

Harms J, Seeger B (1989) Larval development and survival in seven decapod species (Crustacea) in relation to laboratory diet. J Exp Mar Biol Ecol 133:129-139

Hines AH (1991) Fecundity and reproductive output in nine species of Cancer crabs. Can J Fish Aquat Sci 48:267-275 
Joint IR, Pomroy AJ (1983) Production of picoplankton and nanoplankton in the Celtic Sea. Mar Biol 77:19-27

Lehto J, Sulkin S, Strom S, Johnson D (1998) Protists and detrital particles as prey for the first larval stage of the brachyuran crab, Hemigrapsus oregonensis. J Exp Mar Biol Ecol 230:213-224

Levine D, Sulkin SD (1984) Nutritional significance of longchain polyunsaturated fatty acids to the zoeal development of the brachyuran crab Eurypanopeus depressus Smith. J Exp Mar Biol Ecol 81:221-223

Sanders RW, Wickham SA (1993) Planktonic protozoa and metazoa: predation, food quality and population control. Mar Microb Food Webs 7:197-223

Strathmann RR, Strathmann MF (1982) The relationship between adult size and brooding in marine invertebrates. Am Nat 119:91-101

Sulkin SD (1975) The significance of diet in the growth and development of larvae of the blue crab, Callinectes sapidus, under laboratory conditions. J Exp Mar Biol Ecol 20:119-135

Sulkin SD (1978) Nutritional requirements during larval development of the Portunid crab, Callinectes sapidus (Rathbun). J Exp Mar Biol Ecol 34:29-41

Sulkin SD, Epifanio CE (1975) Comparison of rotifers and other diets for rearing early larvae of the blue crab

Editorial responsibility: Jennifer Purcell (Contributing Editor), Cambridge, Maryland, USA
Callinectes sapidus Rathbun. Estuar Coast Mar Sci 3: $109-113$

Sulkin SD, McKeen GL. (1994) Influence of temperature on larval devlopment of four co-occurring species of the brachyuran genus Cancer. Mar Biol 118:593-600

Sulkin SD, Norman K (1976) A. comparison of two diets in the laboratory culture of the zoeal stages of the brachyuran crabs Rhithropanopeus harrisii and Neopanope sp. Helgol Wiss Meeresunters 28:183-190

Sulkin SD, Van Heukelem WF (1980) Ecological and evolutionary significance of nutritional flexibility in planktonic larvae of the deep sea red crab Geryon guinquedens and the stone crab Menippe mercenaria. Mar Ecol Prog Ser 2:91-95

Sulkin SD, Lehto J, Strom S, Hutchinson D (1998) Nutritional role of protists in the diet of first stage larvae of the Dungeness crab Cancer magister. Mar Ecol Prog Ser 169: 237-242

Throndsen J (1979) Productivity and abundance of ultra- and nano-plankton in Oslofjorden. Sarsia 63:273-284

Volkman JK, Jeffrey SW, Nichols PD, Rogers GI, Garland CD (1989) Fatty acid and lipid composition of 10 species of microalgae used in mariculture. J Exp Mar Biol Ecol 128: 219-240

Zar J (1996) Biostatistical analysis, 3rd edn. Prentice-Hall, Englewood Cliffs, NJ

Submitted: January 21, 1999; Accepted: April 6, 1999

Proofs received from author(s): August 17, 1999 